Cite this article as: BMJ, doi:10.1136/bmj.39156.536968.55 (published 10 April 2007)

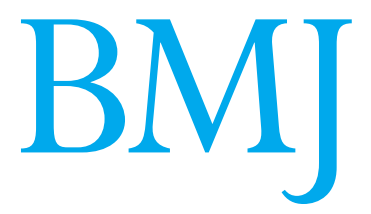

RESEARCH

\title{
Telemonitoring or structured telephone support programmes for patients with chronic heart failure: systematic review and meta-analysis
}

\author{
Robyn A Clark, scholar, ${ }^{1}$ Sally C Inglis, scholar, ${ }^{2}$ Finlay A McAlister, associate professor , ${ }^{3}$ \\ John G F Cleland, professor, ${ }^{4}$ Simon Stewart, professor ${ }^{5}$
}

'Division of Health Sciences, University of South Australia, Adelaide, Australia

${ }^{2}$ Faculty of Health Sciences, University of Queensland,

Brisbane, Australia

${ }^{3}$ Division of General Internal Medicine, University of Alberta, Edmonton, Canada

${ }^{4}$ Academic Cardiology, University of Hull, Hull

${ }^{5}$ Preventative Cardiology Unit, Baker Heart Research Institute, Prahran, Melbourne, Vic 3004, Australia

Correspondence to: S Stewart simon.stewart@baker.edu.au

doi: 10.1136/bmj.39156.536968.55

\section{ABSTRACT}

Objective To determine whether remote monitoring (structured telephone support or telemonitoring) without regular clinic or home visits improves outcomes for patients with chronic heart failure.

Data sources 15 electronic databases, hand searches of previous studies, and contact with authors and experts. Data extraction Two investigators independently screened the results.

Review methods Published randomised controlled trials comparing remote monitoring programmes with usual care in patients with chronic heart failure managed within the community.

Results 14 randomised controlled trials (4264 patients) of remote monitoring met the inclusion criteria: four evaluated telemonitoring, nine evaluated structured telephone support, and one evaluated both. Remote monitoring programmes reduced the rates of admission to hospital for chronic heart failure by $21 \%$ (95\% confidence interval $11 \%$ to $31 \%$ ) and all cause mortality by $20 \%$ ( $8 \%$ to $31 \%$ ); of the six trials evaluating health related quality of life three reported significant benefits with remote monitoring, and of the four studies examining healthcare costs with structured telephone support three reported reduced cost and one no effect.

Conclusion Programmes for chronic heart failure that include remote monitoring have a positive effect on clinical outcomes in community dwelling patients with chronic heart failure.

\section{INTRODUCTION}

Chronic heart failure is a common diagnosis, carries a poor prognosis, and affected patients are major consumers of healthcare resources. ${ }^{1}$ As the prevalence of chronic heart failure is increasing this situation will deteriorate unless new management strategies are developed. ${ }^{2}$ The effectiveness of multidisciplinary non-pharmacological approaches for improving outcomes in patients with chronic heart failure has been well established in over 30 randomised trials. ${ }^{3-7}$ As most of these trials have tested multifaceted approaches, however, it has been difficult to identify the incremental benefits of the components of each intervention. ${ }^{6}$ Nevertheless, it is clear that within most populations access to these programmes is limited as a result of barriers related to funding or geography. ${ }^{8}$ As a result interest is increasing in remote monitoring models for delivering care, which incorporate information communication technology either as telemonitoring (transfer of physiological data such as blood pressure, weight, electrocardiographic details, and oxygen saturation through telephone or digital cable from home to healthcare provider) or as regular structured telephone contacts between patients and healthcare providers, which may or may not include the transfer of physiological data. ${ }^{6}$

Earlier reviews of multidisciplinary programmes for chronic heart failure have been unable to make definitive conclusions about the value of remote monitoring strategies given the paucity of relevant studies and patient numbers at the time of these analyses. ${ }^{56}$ However, several studies with relatively large numbers of patients have since been published, permitting a more detailed analysis. We evaluated the effect of remote monitoring strategies in patients with chronic heart failure and whether the effect differed by the type of technology used for the communication of information.

\section{METHODS}

We updated two earlier systematic reviews that dealt with telemonitoring ${ }^{56}$ by searching 15 electronic databases using search methods recommended by the Cochrane Heart Review Group. ${ }^{9}$ All randomised trials evaluating remote monitoring programmes published between 1 January 2002 and 6 May 2006 were included. Databases searched included the Cochrane library and the Cochrane CENTRAL register of controlled trials, Medline (1 January 2002 to 6 May 2006), Embase, CINAHL (1 January 2002 to 6 May 2006), AMED, ISI web of knowledge, HSTAT, Ingenta, Zectoc, LILACS, and science citation index expanded (to search forward to detect studies citing the original reviews), DARE, national research register, Psych Info, and web of science. We also hand searched the reference lists in 21 published systematic reviews of disease management programmes in chronic heart failure, ${ }^{3-7} 10-26149$ review articles on telephone support 


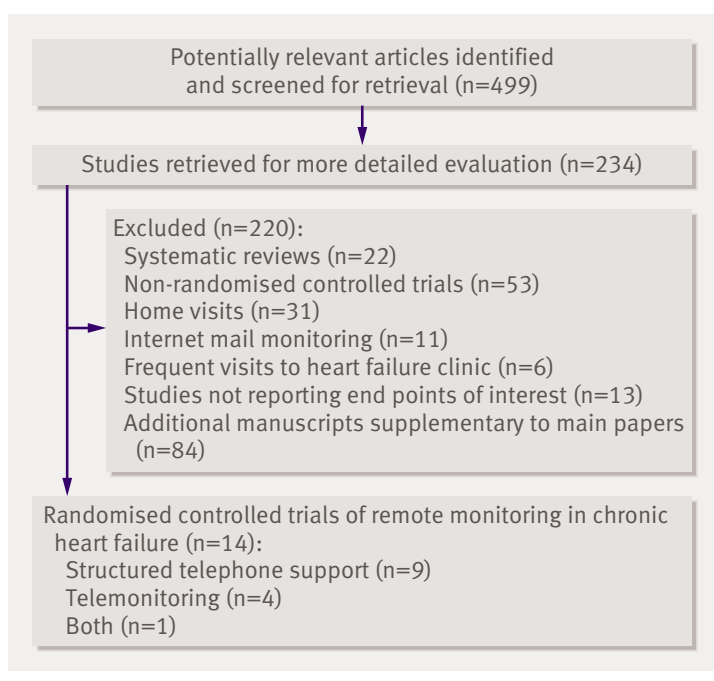

Fig 1 | Flow of study selection

programmes in chronic disease, and those studies identified in our electronic searches that met the inclusion criteria. Unpublished conference proceedings were reviewed and published abstracts were included if the authors replied to our request and sufficient details and outcomes of studies were retrieved. Finally, we communicated with the principal investigators of the identified trials and with national and international experts in the specialty to identify any studies we had potentially missed. We did not restrict study inclusion by language but did limit our review to only randomised controlled trials.

We applied the highly sensitive search strategy from the Cochrane Collaboration. ${ }^{9}$ Keywords for searches of the database included heart failure (exp), cardiac failure (exp), telemedicine (exp), telecare (exp), telemonitoring (exp), teleconsultation (exp), teleconference (exp), telecommunications (exp), case management (exp), comprehensive health care (exp), disease management (exp), health services research (exp), home care services (exp), clinical protocols (exp), patient care planning (exp), nurse led clinics and special clinics (exp), randomised controlled trial (s), controlled clinical trial, random allocation, double blind method, single blind method, clinical trial(s), research design, comparative study, follow-up study, and prospective study.

Search strategies were written for each database and double checked by the second reviewer, under the direction and supervision of a medical librarian.

\section{Types of interventions}

Remote monitoring programmes started by a health professional (medical, nursing, social work, pharmacists) for patients with chronic heart failure living at home were eligible for inclusion if the monitoring was carried out at least once in the first month after hospital discharge, was targeted towards the patient (that is, the patient had to be the person on the telephone), was structured (as opposed to offering telephone follow-up on an "as needed" basis), and was to be delivered as the only aftercare intervention without home visits or more than usual clinic followup. We excluded studies in which the remote monitoring was intended primarily to deal with the problems of care givers rather than of patients. We a priori classified programmes as being structured telephone support if they consisted of standardised telephone contact of patients with chronic heart failure and relied on reporting of symptoms alone, or telemonitoring if they consisted of telephone contact for eliciting symptoms and transmission of physiological data.

Our primary outcomes were all cause mortality, all cause rate of admission to hospital (proportion of patients readmitted to hospital at least once during follow-up), and rate of admission to hospital as a result of chronic heart failure (proportion of patients readmitted to hospital at least once during follow-up). Our secondary outcomes were health related quality of life, cost, and acceptability.

\section{Validity assessment and data abstraction}

Two investigators (RAC, SCI) independently reviewed the results of the searches for study inclusion and extracted data. We excluded any studies in which additional home or clinic visits (more than usual care) were offered to patients in the intervention or control arms. Study quality (particularly method), randomisation, and intervention, were judged using accepted criteria and compared with the review protocol. ${ }^{9}$ Disagreements between the two reviewers were resolved by a third reviewer (SS, FAMcA, or JGFC). Data abstraction was carried out independently and blinded by RAC and SCI, with FAMcA checking extracted data. Overall the inter-rater reliability on key inclusion criteria (randomisation and intervention) was strong ( $\kappa$ score $0.73,95 \%$ confidence interval 0.54 to 0.92$) \cdot{ }^{27}$

\section{Study characteristics and data synthesis}

Owing to the expected differences in patient populations, programme characteristics, and length of followup, we carried out our primary analyses using the DerSimonian and Laird random effects model. Analyses were carried out using RevMan 4.2 (Nordic Cochrane Centre)..$^{9}$ As the outcomes of interest were relatively common we calculated risk ratios and $95 \%$ confidence intervals. The risk difference (difference between observed proportion of the event in the treatment and usual care groups ${ }^{9}$ ) was calculated by subtracting the risk of the event in the usual care group from that of the treatment group. These data are presented with 95\% confidence intervals.

We carried out intention to treat analyses - that is, all patients and their outcomes were analysed in the groups to which they were allocated, regardless of whether they received the treatment. We examined for statistical heterogeneity in each outcome of interest using Cochran's Q test and $\mathrm{I}^{2}$ statistic. Secondary outcomes (expected to be reported less often) were described and tabulated. 


\section{RESULTS}

Overall 234 of 499 citations were reviewed in detail. Of these, $14^{\text {w1-w14 }}$ randomised controlled trials (4264 patients) were eligible for inclusion (fig 1). One trial was three armed $^{\mathrm{w} 1}$; to avoid double counting of the control patients the results for the control arm were shared between the two comparisons for the pooled analysis of all remote monitoring programmes, but all patients in the control arms were counted in each of the sub-analyses (telephone support $v$ usual care, telemonitoring $v$ usual care). Four trials evaluated telemonitoring, ${ }^{\text {w11-w14 }}$ nine evaluated structured telephone support, ${ }^{\text {w2-w10 }}$ and one ${ }^{\mathrm{w} 1}$ evaluated both. Ninety five per cent of the included trials were captured by the Medline search, $2 \%$ from CINAHL, and $3 \%$ from hand searching and contact with experts.

The length of follow-up of these trials ranged from three to 16 months, the mean ages of participants ranged from 57 to 75 years, and all trials enrolled patients with symptoms (New York Heart Association classification range II-IV, left ventricular ejection fraction $<40 \%$ ). Structured telephone support programmes included monitoring of symptoms, medicine management, and education and counselling on lifestyle. All the telemonitoring programmes included transfer of daily data on weight, pulse, blood pressure, and electrocardiographic findings.

The quality of the studies was evaluated using Cochrane recommendations. ${ }^{9}$ The 14 included studies were rated as adequate, reporting $61 \%$ of the recommended quality variables. Six $(42 \%)$ described concealment and some level of blinding of patient or outcome assessors, and seven (50\%) reported completeness of follow-up (table 1).

\section{Quantitative data synthesis All cause mortality}

All 14 trials reported all cause mortality (15 comparisons, 581 deaths, fig 2) and the pooled estimates showed a statistically significant $20 \%$ reduction (95\% confidence interval $8 \%$ to $31 \%$ ) with remote monitoring programmes. The benefits were greater with telemonitoring (risk ratio $0.62,0.45$ to $0.85, \mathrm{P}=0.003$, based on 127 deaths in 807 patients) than with structured telephone support $(0.85,0.72$ to $1.01, \mathrm{P}=0.06$, based on 482 deaths in 3542 patients), although this difference did not

Table 2 |Effect of remote monitoring on chronic heart failure related quality of life, cost, and acceptability to patients

$\begin{array}{lcc}\text { Study } & \text { End point (months) } & \begin{array}{c}\text { Health related quality of } \\ \text { life }\end{array} \\ \text { Cleland et al } 2005 \text { (TEN- } & 400 \text { days } \dagger & -\end{array}$

HMS study $)^{\mathrm{w1}}$

\section{Effect on cost or patient}

$-$

Cost of intervention

-

Acceptability of intervention to patients

$4.1 \%$ of patients refused to accept technology in their homes, $2.9 \%$ of patients asked for equipment to be removed, and $1.8 \%$ discontinued recording. Overall patient acceptance was $91.2 \% .96 \%$ of patients were well satisfied with the system and $97 \%$ found the telemonitoring devices easy to use

\begin{tabular}{|c|c|c|c|c|c|}
\hline Barth $2001^{\text {w4 }}$ & 2 & $\begin{array}{l}\text { Increase in scores on MLHFQ } \\
(P \leq 0.0005)\end{array}$ & - & $\$ 23.60 /$ patient & - \\
\hline Riegel et al $2002^{\mathrm{w} 5}$ & 6 & - & $\begin{array}{l}46 \% \text { reduction in inpatient } \\
\text { costs }(P=0.04)\end{array}$ & $\$ 443 /$ patient & $\begin{array}{l}\text { Patient satisfaction was significantly } \\
\text { higher among people assigned to } \\
\text { intervention group compared with usual } \\
\text { care group }(P=0.01)\end{array}$ \\
\hline Laramee et al $2003^{\mathrm{w} 6}$ & 3 & - & $\begin{array}{l}\$ 2482 / \text { patient (average) } \\
\text { reduction }\end{array}$ & $\begin{array}{l}\begin{array}{l}\$ 228.52 / \text { patient } \\
\text { (average) }\end{array} \\
\text { (a) }\end{array}$ & - \\
\hline Tsuyuki et al $2004^{\mathrm{w} 8}$ & 6 & - & $\$ C 2531 /$ patient reduction & - & - \\
\hline $\begin{array}{l}\text { GESICA investigators } \\
2005^{\mathrm{w} 9} \text { (DIAL trial) }\end{array}$ & 16 (mean) & $\begin{array}{l}\text { Increase in scores on } \\
\text { MLHFQ, mean total score, } \\
\text { intervention } v \text { control } 30.6 v \\
35.0 \text {, mean difference } 4.4 \text {, } \\
95 \% \mathrm{Cl} 1.8 \text { to } 6.9, \mathrm{P}=0.001\end{array}$ & - & - & - \\
\hline Riegal et al $2006^{\mathrm{w} 10}$ & 6 & $\begin{array}{l}\text { MLHFQ (NS), EQ-5D (NS), } \\
\text { depression by PHQ-9 (NS) }\end{array}$ & $\begin{array}{l}\text { No effect on cost of care for } \\
\text { heart failure or all cause acute } \\
\text { care cost }\end{array}$ & - & - \\
\hline De Lusignan et al $2001^{\text {w11 }}$ & 12 & GHQ, CCHFSQ (NS) & - & - & $\begin{array}{l}\text { Video link over standard telephone lines } \\
\text { was not found to be useful by participants }\end{array}$ \\
\hline $\begin{array}{l}\text { Goldberg et al } 2003 \\
\text { (WHARF trial) }^{\text {w12 }}\end{array}$ & 6 & $\begin{array}{l}\text { MLHFQ }(P=0.22), S F-12 \\
\text { (physical score } P=0.15, \\
\text { mental score } P=0.73), \text { HDS } \\
(P=0.57)\end{array}$ & - & - & - \\
\hline Woodend et al $2003^{\mathrm{w} 13}$ & 3 & $\begin{array}{l}\text { Increase in scores on MLHFQ } \\
(P=0.025)\end{array}$ & - & - & Very highly satisfied \\
\hline
\end{tabular}

$\$ 1.00$ (£0.51; €0.75). \$C1.00 (£0.44; €0.65).

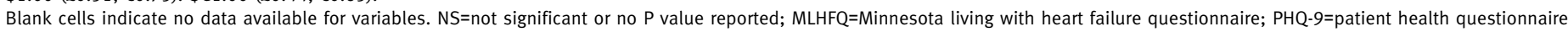
9 item; $\mathrm{GHQ}=$ general health questionnaire; $\mathrm{CHFSQ}=$ chronic heart failure symptomatology questionnaire; HDS=health distress score.

*Variance between baseline and study end point, details provided as included in study.

$\dagger$ Patient acceptability measured at 400 days. 


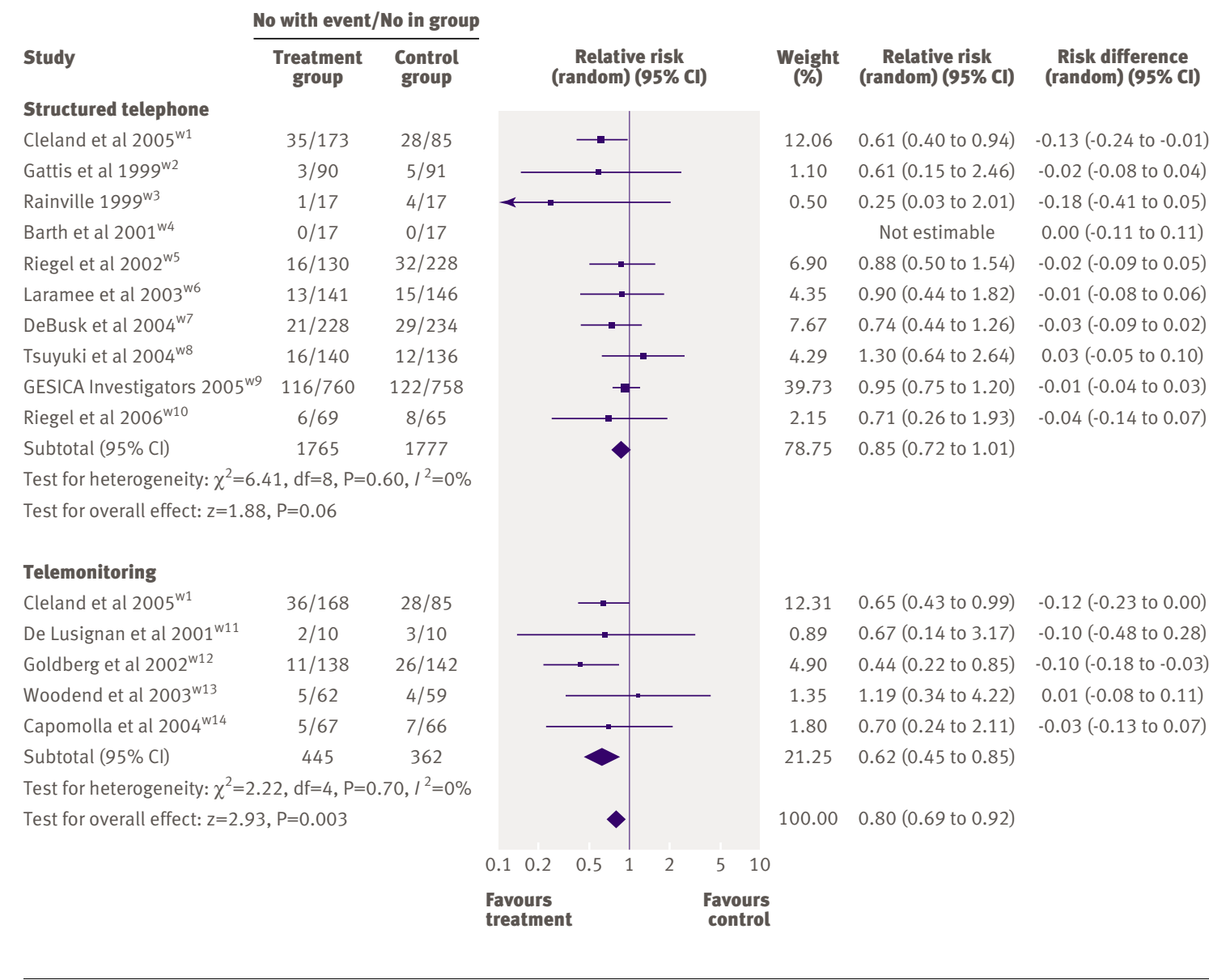

Fig 2 | Effect of remote monitoring on all cause mortality

achieve significance $(\mathrm{P}=0.18)$ using the adjusted indirect comparison method described by Song et al. ${ }^{28}$ Mortality data from these 14 trials showed little heterogeneity $\left(\mathrm{P}=0.56, \mathrm{I}^{2}=0 \%\right)$.

\section{All cause admission to hospital}

Of the eight trials (nine comparisons) that reported rates of all cause admission to hospital (fig 3), none reported a statistically significant result. Even the pooled estimates did not show a significant benefit on this end point with remote monitoring programmes $(0.95,0.89$ to 1.02$)$.

\section{Hospital admissions as a result of chronic heart failure} Nine trials (10 comparisons) reported rates of admission to hospital as a result of chronic heart failure, and although only one reported a statistically significant benefit, all trials showed similar relative reductions $(\mathrm{P}$ for heterogeneity $0.76, \mathrm{I}^{2}=0 \%$ ) and the pooled results showed a reduction of $21 \%(11 \%$ to $31 \%)$ with remote monitoring programmes (fig 4). Although no appreciable difference was found between the relative reductions seen with telemonitoring and telephone support programmes, evidence from randomised trials was insufficient to conclusively state that telemonitoring programmes reduce admissions to hospital since only one of these trials reported this outcome.
Quality of life, cost, adherence, and patient acceptability Only six trials examined the effect of the intervention on health related quality of life (table 2 ). Of these trials, three reported a significant and substantial improvement in quality of life between the intervention and control groups at the end of follow-up. The effect of the intervention on healthcare costs was reported in only four of these trials (all of structured telephone support); however, three of the four trials reported lower healthcare costs for patients randomised to the intervention (table 2). The cost of the intervention was infrequently reported and variation existed between programmes (table 2). None of the trials on telemonitoring reported the cost of the intervention or its effect on healthcare costs. Acceptability of the intervention to the patient was under-reported, with only four trials reporting this outcome (table 2). Three of these trials reported that the intervention was acceptable to patients, with patients from one trial of telemonitoring considering the video link not useful. ${ }^{\text {w11 }}$

An analysis of publication bias using funnel plots showed an unlikely possibility of bias within studies showing a reduction in mortality after remote monitoring.

\section{DISCUSSION}

This systematic review found that remote monitoring programmes for patients with chronic heart failure 
living in the community reduced admissions to hospital and all cause mortality by nearly one fifth while improving health related quality of life, but had no significant effect on all cause admission to hospital. Although few studies have examined economic outcomes, the three studies on structured telephone support suggested that the interventions were economically cost effective Thus, this systematic review builds on earlier ones ${ }^{56}$ of multidisciplinary interventions for chronic heart failure by tackling key issues and uncertainties relating to the specific effect of telephone based programmes. This review is particularly important as remote monitoring programmes provide a potentially feasible option for dealing with the expanding population of patients with chronic heart failure that cannot be accommodated within existing multidisciplinary chronic heart failure clinics owing to constraints caused by geography or resources.

The significant effect of structured telephone support on the risk of admissions to hospital for chronic heart failure (risk differences ranged between $2 \%$ and $35 \%$ ) can be attributed in part to the triage of patients by telemonitoring nurse at the first sign of clinical deterioration, and the consequent immediate intervention of a primary care doctor. ${ }^{\mathrm{w} 5 \mathrm{w} 14}$ Similarly, all trials on telemonitoring in this review involved daily transmission of vital signs, weight, and symptoms at various time points to healthcare providers, thus potentially leading to earlier detection and management of clinical deterioration by the patient or managing health professional. A recent study of rapid up-titration of $\beta$ blockers in 49 patients with chronic heart failure reported that deterioration in symptoms, including weight gain, oedema of the legs, and increasing dyspnoea, were usually present eight to 12 days before admission to hospital. $^{29}$

The lack of effect of remote monitoring programmes on all cause admissions to hospital may require further exploration. This observation is consistent with an earlier meta-analysis. ${ }^{6}$ Importantly this result does not simply reflect a paucity of data as there were more events for this end point (1561 admissions in 3586 patients) than for deaths and admissions to hospital. Reduced mortality will increase the duration of exposure to the risk of admission and will reduce the effect of intervention on this outcome. However, telemonitoring is likely to produce false alarms and pre-emptive admissions in patients who are deteriorating but not yet in crisis and also to lead to early discharge because the patient still has a high level of monitoring at home. Consequently, telemonitoring may be more effective at shortening hospital stay than at reducing admissions. Increased survival and admissions for common comorbid conditions (for example, chronic respiratory disease, fractures from falls, and cancer among participants who were typically elderly $)^{30}$ may also prevent a reduction in the frequency of admissions associated with telemonitoring. Finally, remote monitoring in patients with chronic heart failure focuses on indices specific to that disease and treatment; it may have little effect on other reasons for admission. Whether extending the range of monitoring to provide more comprehensive support will result in a further improvement in health outcomes is yet to be determined.

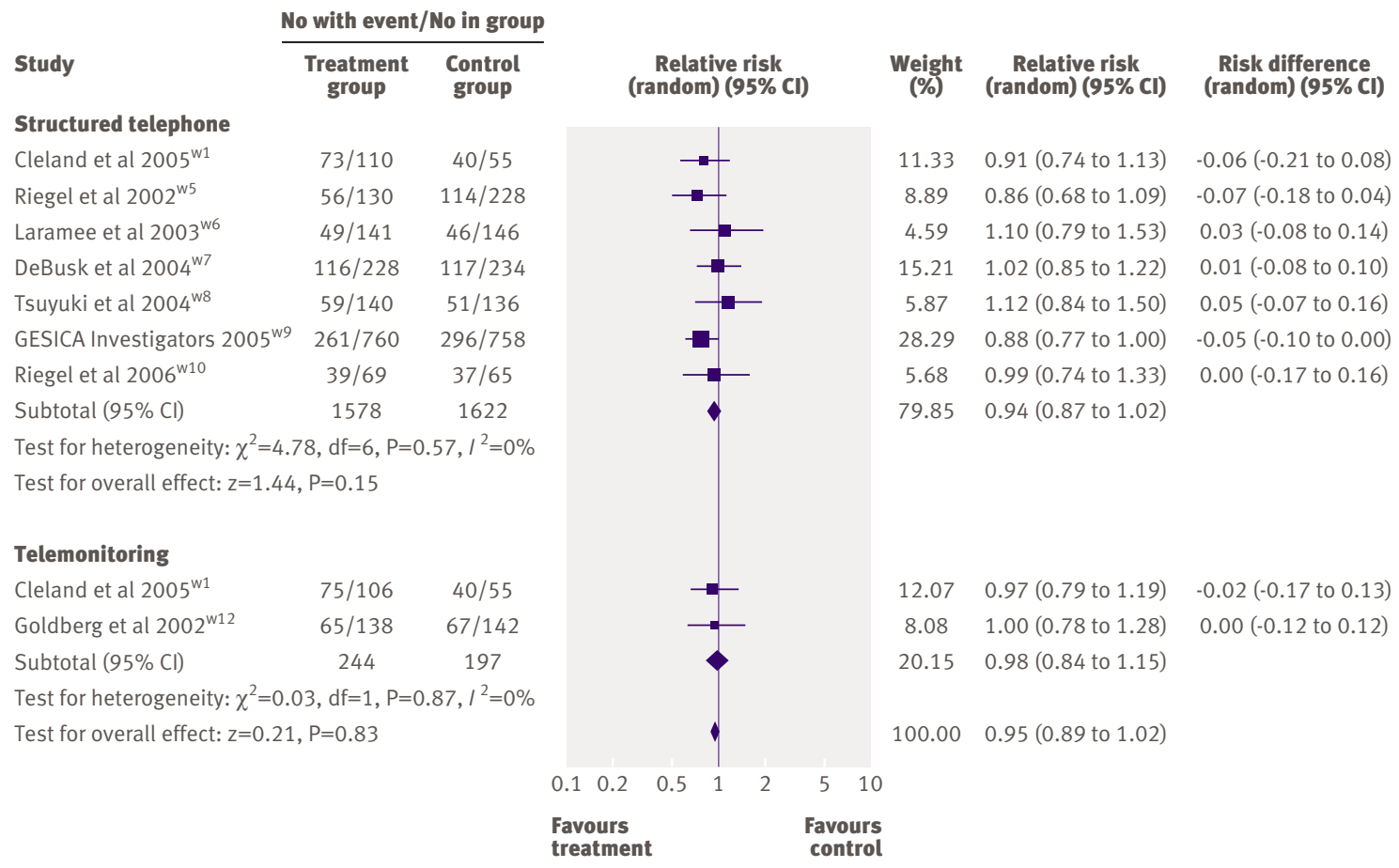




\section{WHAT IS ALREADY KNOWN ON THIS TOPIC}

Systematic reviews on telephone support and

telemonitoring in patients with chronic heart failure have provided inconclusive evidence of benefit

\section{WHAT THIS STUDY ADDS}

Remote monitoring has the potential to improve clinical outcomes in community dwelling patients with chronic heart failure

Quality of life, acceptability, and cost benefits were infrequently reported in these trials. Although those reporting these outcomes showed significant improvements with remote monitoring, future studies of telemonitoring or structured telephone support programmes should be encouraged to incorporate such measures and outcomes in their reporting. The same caveats and recommendations apply to cost data arising from these studies.

\section{Limitations of the study}

A limitation of this review is the relatively small number of studies $(\mathrm{n}=14)$ and participants $(\mathrm{n}=4264)$. In addition, few trials had follow-up beyond six months. Thus our observations on the positive, short term benefits of remote monitoring programmes may not extend to longer term outcomes. However, the hazard ratio for admission to hospital in patients with chronic heart failure is not linear as the greatest risk of readmission in such patients occurs in three to six months. Nevertheless, it is expected that the body of evidence on remote monitoring for chronic heart failure will expand considerably in the next decade as strategies on communicating information become normalised into medical practice and a better understanding is gained of the content of care provided by remote monitoring.

Furthermore, it is anticipated that the following studies will add to the evidence base in this specialty: the as yet unpublished reports on the home or hospital in heart failure ${ }^{31}$ trial, which showed an overall neutral effect on mortality and admissions to hospital; the recent work by the Scalvini et al team in Italy, ${ }^{32}$ which showed a significant reduction in risk of readmission (risk ratio $0.50,95 \%$ confidence interval 0.34 to $0.73 ; \mathrm{P}=0.01$ ); and Riegel et al's ${ }^{\mathrm{w} 10}$ most recent paper, which questions the effect of this type of intervention in non-Caucasian ethnic groups.

\section{Conclusion}

Although we have shown substantial and statistically significant benefits with remote monitoring for patients with chronic heart failure, monitoring is not a treatment but rather a different way of systematically organising effective care. Thus programmes that include remote monitoring should not be seen as a replacement for specialist care ${ }^{8}$ or multidisciplinary chronic heart failure clinics (two interventions that improve outcomes $\left.{ }^{633}\right)$. However, remote monitoring may be of particular benefit to patients who have difficulty accessing specialised care because of geography, transport, or infirmity. ${ }^{834}$

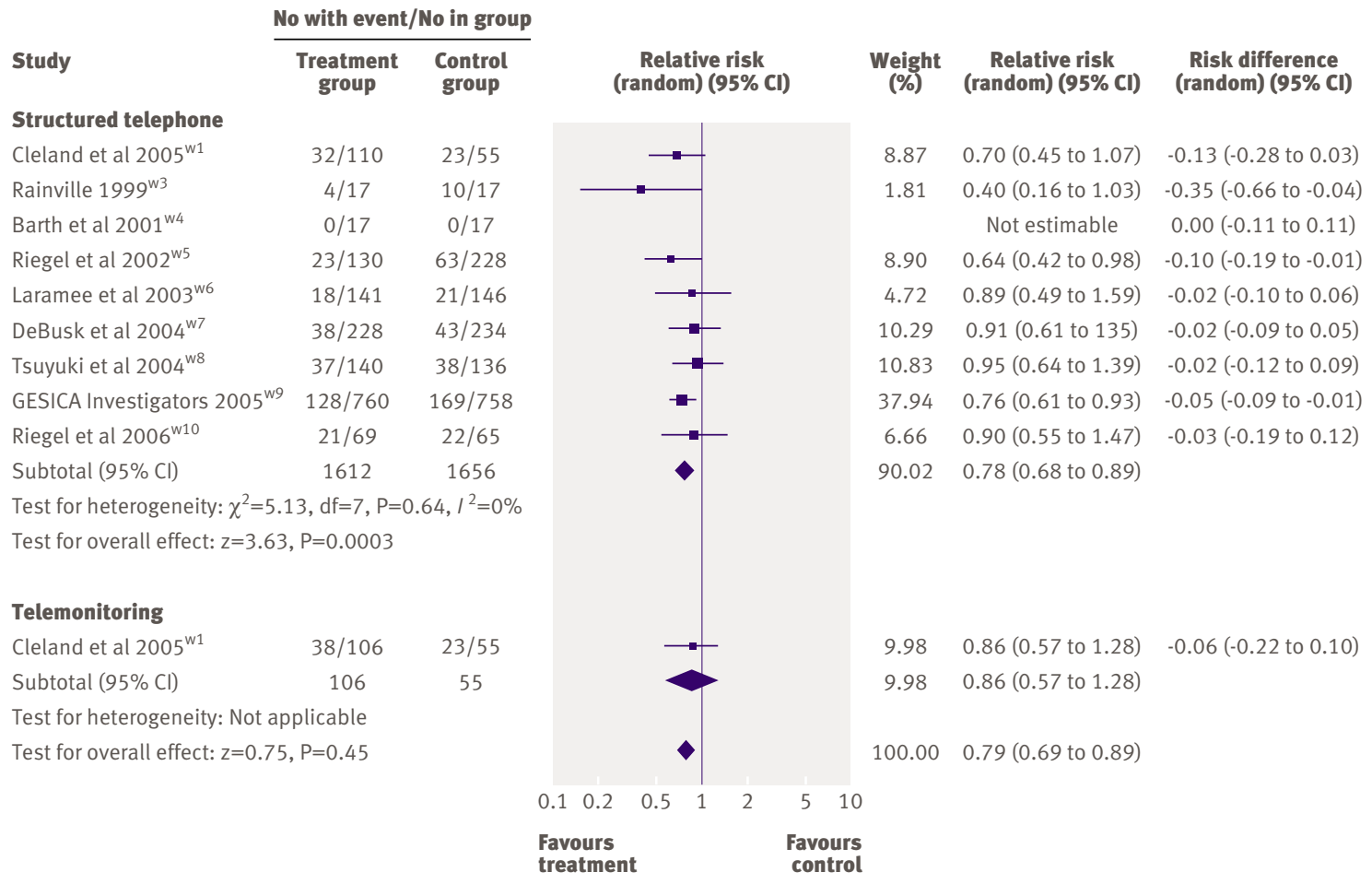


We thank librarian Margaret Goedhart (University of South Australia) for her knowledge and skill in navigating bibliographies and electronic sources, and the following investigators for further data and information from their studies: WA Gattis, LR Goldberg, A Laramee, B Riegel, RT Tsuyuki, A Woodend, and S Scalvini.

Contributors: RAC conceived and designed the study. RAC and SCI reviewed the literature, developed the study protocol, and searched for and abstracted the data. RAC, SCI, SS, and JGFC analysed and interpreted the data. FAMCA assessed the quality of extracted data and was responsible for synthesis and analysis of the data. He will act as guarantor. JGFC hand searched the literature and referred experts to RAC and SCl. All authors contributed to the drafting of the article and revising it for important intellectual content. Funding: RAC is supported by the National Institute of Clinical Studies and the National Heart Foundation of Australia. SCl and SS are supported by the National Health and Medical Research Council and the National Heart Foundation of Australia. FAMcA receives salary support from the Alberta Heritage Foundation for medical research population health scholar programme, the Canadian Institutes of Health Research new investigator programme, and the University of Alberta/Merck Frost/Aventis chair in patient health management. JGFC (within the past five years) was principal investigator transEuropean network homecare management system study and received research funds from the European Union and Phillips Healthcare to carry out the study and has received honorariums from Phillips for speaking on telemonitoring. JGFC is a consultant to the EU sponsored MyHeart project which is part funded by Phillips and other manufacturers of telehealth devices. Ethical approval: Not required.

1 Stewart S, MacIntyre K, Hole DJ, Capewell S, McMurray JJV. More malignant than cancer? Five-year survival following a first admission for heart failure. Eur J Heart Fail 2001;3:315-22.

2 Cleland JGF. Improving patient outcomes in heart failure: evidence and barriers. Heart 2000;84(suppl I):i8-10.

3 Gonseth J, Guallar-Castillon P, Banegas JR, Rodriguez-Artalejo F. The effectiveness of disease management programmes in reducing hospital re-admission in older patients with heart failure: a systematic review and meta-analysis of published reports. Eur Heart / 2004;25(18):1570-95.

4 Gwadry-Sridhar FH, Flintoft V, Lee DS, Lee H, Guyatt GH. A systematic review and meta-analysis of studies comparing readmission rates and mortality rates in patients with heart failure. Arch Intern Med 2004;64:2315-20.

5 Louis AA, Turner T, Gretton M, Baksh A, Cleland JGF. A systematic review of telemonitoring for the management of heart failure. Eur J Heart Fail 2003;5:585-90.

6 McAlister FA, Stewart S, Ferrua J, McMurray JJV. Multidisciplinary strategies for the management of heart failure patients at high risk for admission: a systematic review of randomized trials. J Am Coll Cardiol 2004;44(4);810-9.

7 Phillips CO, Wright SM, Kern DE, Singa RM, Sheppard S, Rubin HR. Comprehensive discharge planning with post discharge support for older patients with congestive heart failure: a meta-analysis. JAMA 2004;291(11):1358-67.

8 Jaarsma T, Stromberg A, De Geest S, Fridlund B, Heikkila J, Martensson I, et al. Heart failure management programmes in Europe. Eur J Cardiovasc Nurs 2006 ;5:197-205.

9 Higgins JPT, Green S, eds. Cochrane handbook for systematic reviews of interventions. In: Cochrane Library. Issue 4. Chichester: John Wiley, 2006.

10 Windham BG, Bennett RG, Gottlieb SH. Care management interventions for older patients with congestive heart failure. $\mathrm{Am}$ J Manag Care 2004:9:447-61.

11 Mistiaen P, Poot E. Telephone follow-up initiated by hospital-based health professionals, for post discharge problems in patients discharged from hospital to home. Cochrane Database Syst Rev 2006;(4):CD004510.

12 Duffy JR, Hoskins LM, Dudley-Brown S. Development and testing of a caring-based intervention for older adults with heart failure. Cardiovasc Nurs 2005;20:325-33.
13 McAlister FA, Lawson FM, Teo KK, Armstrong PW. A systematic review of randomised trials of disease management programs in heart failure. Am J Med 2001;110:378-84.

14 Krishna S, Balas EA, Boren SA, Maglaveras N. Patient acceptance of educational voice messages: a review of controlled clinical studies. Methods Inf Med 2002;41:360-9.

15 Gustafsson F, Arnold JM. Heart failure clinics and outpatient management: review of the evidence and call for quality assurance. Eur Heart J 2004;25(18):1596-604

16 Hamner JB. State of the science: post hospitalization nursing interventions in congestive heart failure. Adv Nurs Sci 2005;28:175-90.

17 Holland R, Battersby J, Harvey I, Lenaghan E, Smith J, Hay L. Systematic review of multidisciplinary interventions in heart failure. Heart 2005;91(7):899-906.

18 Taylor S, Bestall J, Cotter S, Falshaw M, Hood S, Parsons S, et al. Clinical service organisation for heart failure. Cochrane Database of Syst Rev 2005;(2):CD002752

19 Philbin EF. Comprehensive multidisciplinary programs for the management of patients with congestive heart failure. J Gen Intern Med 1999;14:130-5.

20 Tsai AC, Morton S, Mangione CM, Keeler EB. A meta-analysis of interventions to improve care for chronic illnesses. Am J Manag Care 2005;11:478-88.

21 Whellan DJ, Hasselblad V, Peterson E, O'Connor CM, Schmann KA. Meta-analysis and review of heart failure disease management randomized controlled trials. Am Heart J 2005;149(4):722-9.

22 Yu D, Thompson DR, Lee D. Disease management programmes for older people with heart failure: crucial characteristics which improve post-discharge outcomes. Eur Heart J 2006;27:596-612.

23 Bunn F, Byrne G, Kendall S. The effects of telephone consultation and triage on healthcare use and patient satisfaction: a systematic review. BrJ Gen Pract 2005;55:956-61.

24 Murray E, Burns J, See Tai S, Lai R, Nazareth I. Interactive health communication applications for people with chronic disease. Cochrane Database Syst Rev 2005;(4):CD004274

25 Duffy JR, Hoskins LM, Chen Mei-Chun. Nonpharmacological strategies for improving heart failure outcomes in the community: a systematic review. J Nurs Care Qual 2004;19:349-60.

26 Phillips CO, Singa RM, Rubin HR, Jaarsma T. Complexity of programs and clinical outcome of heart failure disease management incorporating specialist nurse-led heart failure clinics. A metaregression analysis. Eur J Heart Fail 2005;7:333-41.

27 Landis JR, Koch GG. The measurement of observer agreement for categorical data. Biometrics 1977;33:159-74.

28 Song F, Altman D, Glenny A, Deeks J. Validity of indirect comparison for estimating efficacy of competing interventions: empirical evidence from published meta-analyses. BMJ 2003;326:472.

29 Spaeder J, Najjar S, Gerstenblith G, Hefter G, Kern L, Palmer JG. Rapid titration of carvedilol in patients with congestive heart failure: a randomized control trial of automated telemedicine versus frequent out-patient clinic visits. Am Heart / 2006;151:844.e1-10.

30 Davis RC, Hobbs FD, Kenkre JE. Prevalence of left ventricular systolic dysfunction and heart failure in high risk patients: community based epidemiological study. BM/ 2002;325:1156-9.

31 Mortara A, Pinna GD, Capomolla S, Maestri R, Johnson P, La Rovere MT, et al. Rehabilitation and models of domiciliary care of patients with chronic heart failure: preliminary results of the $\mathrm{HHH}$ study. Monaldi Arch Chest Dis 2005;64:143-5.

32 Scalvini S, Zanelli E, Volterrani M, Martinelli G, Baratti D, Buscaya O, et al. A pilot study of nurse-led, home-based telecardiology for patients with chronic heart failure. J Telemed Telecare 2004;10:113-7.

33 Ezekowitz J, van Walraven C, McAlister FA, Armstrong PW, Kaul P. Impact of specialist follow-up in outpatients with congestive heart failure. CMA/ 2005;172:189-94.

34 Cleland JGF. Patients with treatable malignant disease-including heart failure-are entitled to specialist care. CMA/ 2005;172:207-9.

Accepted: 19 February 2007 


\section{Table 1 |Description of studies included in systematic review and meta-analysis}

Study

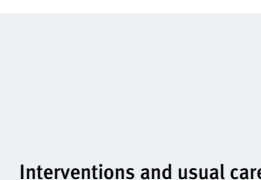

Interventions and usual care

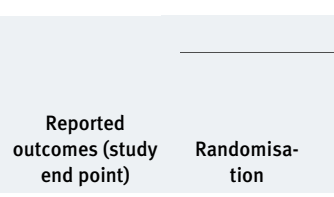

end point)

\section{Study quality}

$\begin{array}{cc}\begin{array}{c}\text { Blinding } \\ \text { of } \\ \text { patients }\end{array} & \begin{array}{c}\text { Complete } \\ \text { and }\end{array} \\ \text { ness of } \\ \text { assessors } & \text { follow-up }\end{array}$

Structured telephone (on

basis of symptom

reporting) and

telemonitoring (on basis

of symptom and sign

monitoring):

\section{Cleland et al 2005}

(TEN-HMS study) ${ }^{\mathrm{w} 1}$
426 patients (mean age 67 years) with a recent admission for heart

failure and left ventricular ejection fraction $<40 \%$ (Germany, Netherlands, United Kingdom)
Patients assigned to nurse telephone support arm received a telephone call each month by a heart failure specialist nurse to assess symptoms and current drugs. Patients assigned to

telemonitoring received nurse telephone support and had their weight, blood pressure, and electrocardiogram monitored twic daily. Usual care consisted of a management plan forwarded to patient's primary care physician, who was asked to implement it. If the practice involved nurse titration of drugs this was allowed. Patients were assessed at a research clinic every four months; contact with clinic was discouraged between visit

$\begin{array}{lllll}\begin{array}{l}\text { Mortality, } \\ \text { readmission to } \\ \text { hospital, } \\ \text { compliance with } \\ \text { intervention } \\ (15 \text { months })\end{array} & \begin{array}{l}\text { Random } \\ \text { permuted } \\ \text { blocks }\end{array} & \begin{array}{l}\text { After consent and } \\ \text { collection of baseline } \\ \text { data an independent } \\ \text { statistical centre was } \\ \text { contacted }\end{array} & \text { NS } & \begin{array}{l}1 \% \text { lost to } \\ \text { follow-up }\end{array} \\ & & & \\ & & \\ \end{array}$

Structured telephone

(on basis of symptom reporting):

Gattis et al 1999 (PHARM study) $^{\text {w2 }}$

\begin{tabular}{ll}
\hline Rainville $1999^{\text {w3 }}$ & 34 patients aged $\geq$ \\
& 50 years (mean age \\
& 70 years) discharged \\
& from hospital with heart \\
& failure (United States)
\end{tabular}

$\begin{array}{ll}\text { Barth et al 2001 } 20 & 34 \text { patients (mean age } \\ & 75 \text { years) discharged } \\ & \text { from acute care to home } \\ & \text { with primary diagnosis of } \\ \text { chronic heart failure } & \text { (United States) }\end{array}$

\section{1 patients (mean age} 67 years) with heart

failure being evaluated in cardio
Clinical pharmacist led drug review and patient education. Regularly scheduled telephone contact (at 2,12, and 24 weeks) to detect clinical deterioration early. Control group received usual care that did not include pharmacist providing recommendations on drug therapy to attending physician or providing education to patient. Patient assessment and education were provided by attending physician, physician assistant, or nurse practitioner Patient was contacted by pharmacist by telephone to identify clinical events

Usual care plus pharmacist led drug review, patient education, drug management before discharge and at days 3, 7, 30, and 90, and 12 months. Usual care consisted of routine care and preparation for discharge, including written prescriptions, physician discharge instructions, and nurse review of diet, treatment plans, and drugs. Nurses provided patient with computer generated drug information sheets. Patients were contacted by a pharmacist at 30 days, 90 days, and 12 months to determine readmissions

Structured nurse managed telephonic post-discharge programme Mortality, involving predischarge educati follow-up. Structured interaction at 72 hours, 144 hours, and then fortnightly. Control group received routine discharge teaching at time of discharge as per hospital procedure. Patients were contacted at 2 months for collection of data

\section{Mortality,}

readmission to

prescription

6 months)

generated

Assignment reveale

after provision of consen

Yes;

(United States)

\section{Mortality,}

readmission to

hospital,

functional

assessment score

(12 months) readmiss

physician and

emergency

department visits,

$\begin{array}{lll}\begin{array}{l}\text { Method not } \\ \text { stated }\end{array} & \text { Unclear } ; \text { NS } & \begin{array}{l}2.9 \% \text { lost to } \\ \text { follow-up }\end{array}\end{array}$

quality of life, cost

of intervention

(3 months)

Riegel et al $2002^{\mathrm{w} 5} \quad 358$ patients (mean aged 74 years) discharged from hospital with heart failure (United States)

Telephonic case management by registered nurse using decision support software, involving patient education and counselling and liaison with primary care physician. Patients were telephoned within 5 days of discharge and thereafter at a frequency guided by software and case manager (mean 17 calls). Usual care was not standardised, and no formal telephonic case management was in existence at these institutions. These patients presumably received some education on heart failure management before hospital discharge

\section{Mortality,}

readmission to

hospital,

\begin{tabular}{|c|c|c|}
\hline $\begin{array}{l}\text { Physicians } \\
\text { were unit of } \\
\text { randomisa- }\end{array}$ & Unclear & $\begin{array}{l}\text { Physicians NS } \\
\text { blinded; } \\
\text { NS }\end{array}$ \\
\hline
\end{tabular}

physician and tion, method

emergency not stated

department visits,

inpatient costs,

patient

satisfaction

(6 months)

\begin{tabular}{|c|c|}
\hline Laramee et al $2003^{\mathrm{w} 6}$ & $\begin{array}{l}287 \text { patients (mean age } \\
71 \text { years) admitted to } \\
\text { hospital with primary or } \\
\text { secondary diagnosis of } \\
\text { chronic heart failure, left } \\
\text { ventricular systolic } \\
\text { dysfunction } ₫ 40 \% \text { or } \\
\text { radiological evidence of } \\
\text { pulmonary oedema } \\
\text { (United States) }\end{array}$ \\
\hline DeBusk et al $2004^{\mathrm{w} 7}$ & $\begin{array}{l}462 \text { patients (mean age } \\
72 \text { years) admitted to } \\
\text { hospital with provisional } \\
\text { diagnosis of chronic } \\
\text { heart failure from Kaiser } \\
\text { Permanente (United } \\
\text { States) }\end{array}$ \\
\hline
\end{tabular}

Telephonic case management carried out by one nurse case manager for chronic heart failure, involving four major components: early discharge planning, patient and family education on chronic heart failure, promotion of optimal drugs for chronic heart failure and 12 weeks of telephone follow-up. Usual care consisted of standard care typical of a tertiary care hospital. It included inpatient social service evaluation (25\%), dietary consultation (15\%), physiotherapy or occupational therapy $(17 \%)$, and education on drugs and chronic heart failure by nurses. Post-discharge was carried out by the patient's local physician ( $44 \%$ received some home care services)

Standardised telephonic physician directed nurse managed case Mortality, management, involving lifestyle education and drug management readmission to for chronic heart failure. Patients contacted weekly for 6 weeks, biweekly for 8 weeks, and then monthly and bimonthly. Usual care not clearly defined, but was provided by participating Kaiser Permanente medical centres, seemed to involve a high frequency of all of kinds of follow-up clinic visits (13 in 12 months after Mortality, readmission to hospital, inpatient and outpatient

costs, drug

prescription and

adherence

(3 months) not stated

hospital,

emergency and outpatient department visits, prescription of recommended pharmacotherapy (12 months)

$\begin{array}{llll}\text { Sealed } & \text { Research staff not } & \text { NS; Yes } & \text { NS } \\ \text { assignment } & \text { associated with } \\ \text { using Efron } & \text { delivering intervention } \\ \text { procedure } & \begin{array}{l} \\ \text { provided sealed } \\ \text { assignment }\end{array}\end{array}$

of first 42

patients,

randomisation

in blocks of

in blocks
eight

assignment 
Tsuyuki et al $2004^{\mathrm{w} 8} \quad 276$ patients (mean age 72 years) discharged from hospital with heart failure (Canada)
Early discharge planning with provision of adherence aids, patient Mortality, education, regularly scheduled telephone contact with local research coordinator at 2 and 4 weeks then monthly thereafter fo 6 months. Recommendations to see primary care physician if not receiving target dose of angiotensin converting enzyme inhibitor or deterioration. Patients assigned to usual care received a pamphlet on general heart disease before discharge, but no formal counselling beyond what was routine at the hospital. Patients were contacted monthly for 6 months to ascertain clinical events GESICA Investigators 1518 outpatients (mean Nurses trained in management of patients with chronic heart 2005 (DIAL trial) $^{\text {w9 }}$ age 65 years) with stable (Argentina) 6 months)

Mortality, life (mean
Nurses trained in management of patients with chronic heart
failure carried out structured telephone follow-up involving adherence to diet and treatment, monitoring of symptoms, control of fluid retention, and daily physical activity. Patients were contacted four times in the first fortnight and then as needed. Patients in control group were followed by their attending cardiologists and received care similar to the intervention group

\begin{tabular}{ll}
\hline Riegel et al $2006^{\text {w10 }}$ & 134 Hispanic patients \\
& (mean age 72 years) \\
& admitted to hospital with \\
& chronic heart failure \\
& (United States)
\end{tabular}

Education, monitoring, and guidance by bilingual-bicultural Mexican-American registered nurses by telephone case management standardised using decision support software. Patients were contacted on average within 5 days of discharge and thereafter at a frequency guided by the software and nurse case manager over a 6 month period (mean 13.5 calls to patients and 8.4 additional calls to families). Printed educational material was provided monthly and on request in relevant language. Usual care was not standardised and no formal disease managemen programme existed at these institutions. Standard of usual care was that patients were educated about heart failure management before discharge, assuming that nurse spoke patient's language or someone bilingual was available to translate. In reality, only a small portion of staff were bilingual so much of the discharge instruction was provided in writing. Typical discharge instructions included a drug list and institution specific discharge instruction sheet with handwritten notes to follow a low sodium diet and contact the physician if symptoms occur

Telemonitoring (on basis of symptom and sign monitoring):

\begin{tabular}{|c|c|c|c|c|c|c|c|}
\hline $\begin{array}{l}\text { De Lusignan et al } \\
2001^{\text {w11 }}\end{array}$ & $\begin{array}{l}20 \text { patients (mean age } \\
75 \text { years) with heart } \\
\text { failure confirmed by } \\
\text { cardiologist, identified } \\
\text { from database of } \\
\text { academic general } \\
\text { practice (United } \\
\text { Kingdom) }\end{array}$ & $\begin{array}{l}\text { Telemonitoring of vital signs (pulse, blood pressure, weight) and } \\
\text { clinical status assessed daily by nurses along with video } \\
\text { consultations with a nurse weekly for } 3 \text { months, fortnightly for } \\
3 \text { months, then monthly. Usual care consisted of standard general } \\
\text { practice treatment; in addition they had pulse, blood pressure, } \\
\text { and weight measured quarterly. They were evaluated in the same } \\
\text { manner as the intervention group }\end{array}$ & $\begin{array}{l}\text { Mortality, } \\
\text { compliance with } \\
\text { intervention and } \\
\text { drugs, patient } \\
\text { satisfaction, } \\
\text { quality of life ( } \\
12 \text { months) }\end{array}$ & $\begin{array}{l}\text { Random table } \\
\text { allocation }\end{array}$ & Unclear & NS & NS \\
\hline $\begin{array}{l}\text { Goldberg et al } 2002 \\
\text { (WHARF trial) }^{\text {w12 }}\end{array}$ & $\begin{array}{l}280 \text { patients (mean age } \\
59 \text { years) admitted to } \\
\text { hospital with NYHA class } \\
\text { III-IV, with left ventricular } \\
\text { ejection fraction } \leq 35 \% \\
\text { (United States) }\end{array}$ & $\begin{array}{l}\text { Daily transmission of weight and symptoms using a customised } \\
\text { monitor; data were reviewed daily by nurses and concerns } \\
\text { reported to physician. Patients in control group were instructed to } \\
\text { contact their physician for weight increases of more than a } \\
\text { prespecified amount or if their symptoms of heart failure } \\
\text { worsened. They had a weight log to bring to visits. Follow-up visits, } \\
\text { other than study visits, were at the discretion of the treating } \\
\text { physician. Telephone contacts were permitted at the discretion of } \\
\text { the treating physician or nurse }\end{array}$ & $\begin{array}{l}\text { Mortality, } \\
\text { readmission to } \\
\text { hospital, } \\
\text { emergency } \\
\text { department visits, } \\
\text { quality of life, } \\
\text { patient } \\
\text { satisfaction, } \\
\text { compliance with } \\
\text { intervention } \\
\text { (mean } 6 \text { months) }\end{array}$ & $\begin{array}{l}\text { Method not } \\
\text { stated }\end{array}$ & Unclear & NS ; Yes & $\begin{array}{l}11 \% \text { lost to } \\
\text { follow-up }\end{array}$ \\
\hline $\begin{array}{l}\text { Woodend et al } \\
2003^{\mathrm{w} 13}\end{array}$ & $\begin{array}{l}121 \text { patients (mean age } \\
68 \text { years) with } \\
\text { symptomatic heart } \\
\text { failure (NYHA class II or } \\
\text { greater) (Canada) }\end{array}$ & $\begin{array}{l}\text { Daily transmission of weight and periodic transmission of } \\
\text { electrocardiogram and blood pressure. Weekly video conferences } \\
\text { by telehome care nurse. Video conferences more frequent in first } \\
\text { few weeks and tapered over } 3 \text { months. Usual care was not } \\
\text { described }\end{array}$ & $\begin{array}{l}\text { Mortality, } \\
\text { readmission to } \\
\text { hospital, quality of } \\
\text { life, emergency } \\
\text { department visits, } \\
\text { patient } \\
\text { satisfaction ( } \\
3 \text { months) }\end{array}$ & $\begin{array}{l}\text { Method not } \\
\text { stated }\end{array}$ & Unclear & NS & NS \\
\hline $\begin{array}{l}\text { Capomolla et al } \\
2004^{\text {w14 }}\end{array}$ & $\begin{array}{l}133 \text { patients (mean age } \\
57 \text { years) discharged } \\
\text { from specialist chronic } \\
\text { heart failure unit to home } \\
\text { (Italy) }\end{array}$ & $\begin{array}{l}\text { Daily communication of vital signs (including weight, systolic } \\
\text { blood pressure, heart rate) and symptoms with review by nurses } \\
\text { and physicians. Access to medical staff by phone as needed was } \\
\text { available. Usual care consisted of referral to patient's primary care } \\
\text { physician or cardiology department at discharge. Post-discharge } \\
\text { care was governed by care provider }\end{array}$ & $\begin{array}{l}\text { Mortality, } \\
\text { readmission to } \\
\text { hospital, } \\
\text { emergency } \\
\text { department visits, } \\
\text { compliance with } \\
\text { intervention ( } \\
12 \text { months) }\end{array}$ & $\begin{array}{l}\text { Method not } \\
\text { stated }\end{array}$ & Unclear & NS & NS \\
\hline
\end{tabular}
generated hospital, drug sequence adherence, using block physician and randomisation emergency stratified by department visits, study site cost analysis ( readmission to Permuted hospital, quality of 16 months) block randomisation After provision of NS; Yes $\quad 0.5 \%$ lost to consent, patient's follow-up office follow-up lists, stratified according to patient's cardiologist

\section{Mortality,} Sealed readmission to envelopes hospital, cost of care, self reported health related quality of life and depression ( 6 months) attached to sequential data forms

Sealed envelopes NS; Yes No losses to

opened after collection of

baseline data 